\title{
INCREASING RAILWAY ENERGY EFFICIENCY: A THREE-LEVEL METHOD
}

\author{
R.M. PAULUSSEN ${ }^{1}$, G.F. TEN HARVE 2 , T. PLOEG ${ }^{3}$ \& A. ZOETEMAN ${ }^{2}$ \\ ${ }^{1}$ ARCADIS, Amsterdam, The Netherlands. \\ ${ }^{2}$ ProRail, TU Delft, The Netherlands. \\ ${ }^{3}$ DNV GL, Arnhem, The Netherlands.
}

\begin{abstract}
Energy efficiency in railway operation has been a topic of high interest for years. Lowering energy costs can make railway operation not only more sustainable, but also more competitive towards other modalities. Energy efficiency can be reached in two ways: system efficiency and operational efficiency. Innovation can be found in combining the right system measures with the right operational measures. Introducing the right system measures can even lead to energy efficiency independent of operational strategies, such as coasting and regenerative braking.

Rail infra providers struggle with the question which innovations - system, operational or both will bring them closer to their targets. To determine which measures will contribute best, the authors developed a new universal method based on energy efficiency at three levels: individual rolling stock performance, rolling stock performance in networks and operational strategies.

The authors used this three-level method to study the energy efficiency effect of a system change from the current $1,500 \mathrm{~V}_{\mathrm{DC}}$ to a $3 \mathrm{kV}_{\mathrm{DC}}$ traction power supply system, including operational strategies. The results of the study revealed that in the Netherlands this system change will result in a return on investment (ROI) within 15 years and a reduction of energy consumption ranging up to $20 \%$.

Keywords: energy efficiency, return on investment, simulation study, social cost-benefit analysis, system changeover.
\end{abstract}

\section{INTRODUCTION}

Energy efficiency in railways has been a major topic in the past years. Due to the high investment costs in infrastructure and rolling stock, operational strategies are in favour for application. However, will this kind of strategies still work when system changeover is applied?

In the Netherlands, the current traction voltage is $1,500 \mathrm{~V}_{\mathrm{DC}}$. In the past a changeover towards a $25 \mathrm{kV}_{\mathrm{AC}}$ system was considered in order to be able to meet the future increasing traction power demand. However, the idea of a changeover from $1,500 \mathrm{~V}_{\mathrm{DC}}$ towards a $25 \mathrm{kV}_{\mathrm{AC}}$ system was put aside because of high costs and difficulty in changing a DC system into an AC system.

The introduction of increased train frequencies leads to high investments in the existing $1,500 \mathrm{~V}_{\mathrm{DC}}$ network. With that, a question arises if a changeover to a $3 \mathrm{kV}_{\mathrm{DC}}$ network could be an alternative: are the benefits - lower energy losses and higher performance - feasible and will it deliver enough return on investment (ROI)?

To increase energy efficiency in train operation Dutch Railways has introduced operational strategies like coasting to make train drivers aware of energy efficient ways of driving. The efficiency of such operational strategies depends strongly on individual train driver's \footnotetext{
WIT The

www.witconferences.com
} 
behaviour and the fit into the timetable. Will these strategies still work after a changeover from $1,500 \mathrm{~V}_{\mathrm{DC}}$ towards $3 \mathrm{kV}_{\mathrm{DC}}$ ?

This article deals with the energy efficiency part of the changeover and the relation between system voltage and operational strategies. To determine which measures - which voltage in combination with which operational strategies - will contribute best to energy efficiency, the authors developed a new universal method based on energy efficiency at three levels:

1. Individual rolling stock performance. The performance of rolling stock on energy consumption and energy recuperation is defined, thereby determining its maximum performance.

2. Rolling stock performance in networks. Insight is given in the performance of rolling stock in networks by studying its interactions with those networks. The difference between the competence of individual rolling stock and the performance of rolling stock in a network defines the energy opportunity gap.

3. Operational strategies. Different operational models in combination with different system topologies are studied to determine which minimizes the energy opportunity gap the most.

In the next sections these three levels will be discussed in relation to the possible changeover from $1,500 \mathrm{~V}_{\mathrm{DC}}$ towards $3 \mathrm{kV}_{\mathrm{DC}}$.

\section{INDIVIDUAL ROLLING STOCK PERFORMANCE}

This section deals with the first step of increasing energy efficiency for individual rolling stock: the possible contribution of rolling stock to regenerative braking energy, and the relationship between available power and system voltage. As individual rolling stock is part of a network and operational strategies, the type of rolling stock and service performed determine the influence on the energy consumption and regeneration: freight trains and intercity services operate in more or less continuous power consumption mode. Stop services, on the contrary, are accelerating or decelerating most of the time and therefore are of great interest in increasing energy efficiency by reusing the regenerative braking energy.

\subsection{Regenerative braking}

In order to determine the contribution of rolling stock to its own regenerative braking possibilities, a few boundaries of these possibilities must be clarified. Individual rolling stock represents a total mechanical braking power $P_{m}$ which is equal to

$$
P_{m}=F \cdot v=m \cdot a \cdot v=\frac{1}{\eta} U \cdot I_{\text {max }}=\frac{P_{E D, \max }}{\eta}
$$

The electrodynamic braking power $\left(P_{m}\right)$ is limited at a certain velocity by a certain electrical power $P_{E D \text {,max }}$. The relation between the mechanical and electrical braking power is determined by the efficiency $\eta$.

So, to optimize electrodynamic regenerative braking, deceleration should be adapted to the ability of the train system to transform mechanical braking force into electrical power. As the mass of the train is to be considered constant during braking, only the deceleration $(a)$ and velocity $(v)$ are left to maximize the electric regenerative braking energy. 


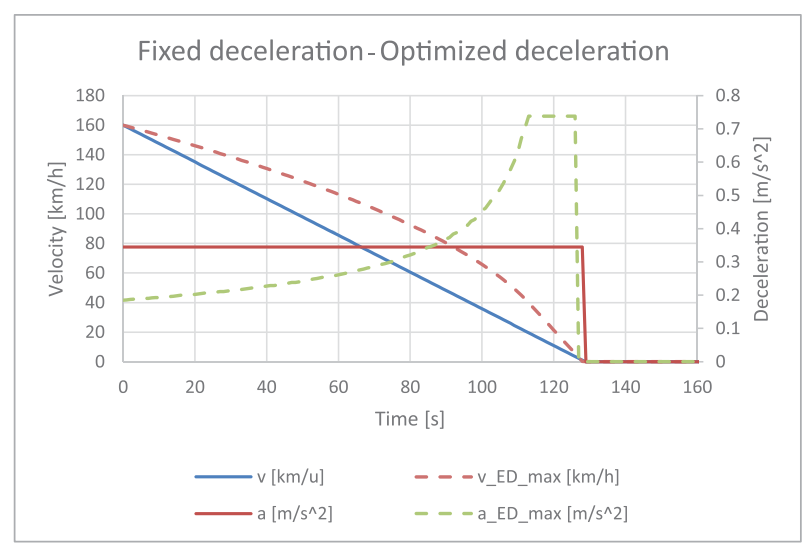

Figure 1: Individual rolling stock, constant deceleration $(a)$ versus optimized deceleration (a_ED_max, dashed lines) for electrodynamic braking.

This may lead to the first conclusion that braking with a constant deceleration leads to adding up mechanical braking to electrodynamical braking at high speed and to underachievement of electrodynamical braking at lower speed. As an example of this mechanism, a combination of Sprinter Light Train (SLT) of Dutch Railways is presented: 2,805 kW of maximum mechanical braking power at $40 \mathrm{~km} / \mathrm{h}$. To utilize the entire electrodynamic braking force during braking, the deceleration must be speed dependent (optimized). Speed-dependent and fixed decelerations, having the same braking time, are shown in Fig. 1.

The difference in braking energy - from 160 to $0 \mathrm{~km} / \mathrm{h}$ - between fixed $\left(0.345 \mathrm{~m} / \mathrm{s}^{2}\right)$ and optimized deceleration for this train set is in favour of optimized deceleration: $65 \mathrm{kWh}$ (100\%) versus $83 \mathrm{kWh}(128 \%)$. Based on the measurements by Dutch Railways the SLT stopping services are modelled with a constant braking deceleration of $0.5 \mathrm{~m} / \mathrm{s}^{2}$ [1] leading to $50 \mathrm{kWh}(100 \%)$ versus $83 \mathrm{kWh}(166 \%)$.

Introducing a constant deceleration of $0.5 \mathrm{~m} / \mathrm{s}^{2}$ for this rolling stock will lead to utilization of $60 \%$ of the available electrodynamic braking energy. For intercity services - based on Dutch Railway measurements of VIRM rolling stock [2] - the deceleration is modelled with $0.35 \mathrm{~m} / \mathrm{s}^{2}$, which leads to an utilization of $87 \%$ of the available electrodynamic braking energy.

Based on this first step in the first level of energy efficiency it can be concluded that the characteristic of the individual train, together with the way a parameter of deceleration is used, in the real world as well as in simulation tools, determines the regenerative braking energy available to the network.

\subsection{System voltage}

In the Netherlands, the system voltage of the conventional rail system is $1,500 \mathrm{~V}_{\mathrm{DC}}$. All trains in the network have to comply with the current limitation of 4,000 A according to EN50388. This means that train performance is decreased when a train initially wants to draw more current than 4,000 A. In fact, the maximum power of the VIRM and SLT rolling stock is only available above $1,900 \mathrm{~V}_{\mathrm{DC}}$. In Fig. 2 this voltage dependency of the tractive effort is presented for a combination of 10 coaches SLT. 


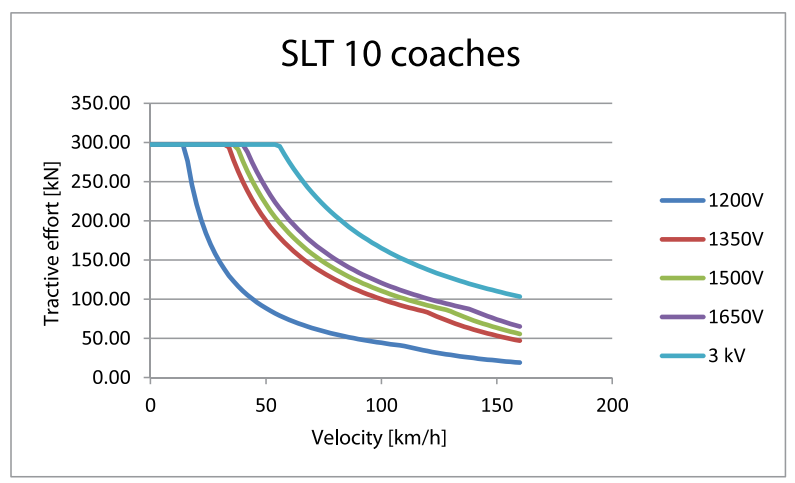

Figure 2: Tractive effort - speed characteristics depending on train voltage.

This formation of SLT rolling stock runs without power limitation in a $3 \mathrm{kV}_{\mathrm{DC}}$ system. When operated under $1,500 \mathrm{~V}_{\mathrm{DC}}$, however, its performance is limited by the train voltage in the network. This performance limit leads to an extended power draw from the network when accelerating. The difference in mechanical power available between 1,200 V and $3 \mathrm{kV}$ is $1,157 \mathrm{~kW}$ versus $4,462 \mathrm{~kW}$. At velocities above $110 \mathrm{~km} / \mathrm{h}$ this difference will increase further.

Based on this second step in the first level of energy efficiency it can be concluded that the tractive effort characteristic of the individual train is voltage dependent and must be considered when comparing different power supply systems.

\section{ROLLING STOCK PERFORMANCE IN NETWORKS}

This section deals with the performance of rolling stock in a network by studying its interactions with that same network. The difference between the performance of individual rolling stock and rolling stock in a network defines the energy opportunity gap, which is network dependable. The main question in this section is, what is responsible for the energy opportunity gap?

Although the capability of the network depends on many parameters, only three of them are regarded to be responsible for the efficiency of the network. First, the operational voltage of the network and the voltage-current limitation of the regenerative braking power. Both accommodate the reach of the braking energy in the network. Second, the network configuration consisting of paralleling points, single or more tracks in parallel and the overall cross section of the catenary and return system. These characteristics of the network determine the efficiency of the reach of the braking energy in the network. Finally, the operation of the network, which can be clarified by an example. If two trains arrive at the same time at the same station, the regenerative power of these trains must be transported elsewhere in the network. If the first train leaves and is able to consume the regenerative power from the second train the regenerative power is used within a small circuit, avoiding high losses. So, operation of the network in combination with the network topology can influence the energy consumption of the network. This third parameter introduces the question whether it is possible to uncouple the operation of the network and the ability to increase energy efficiency. The benefit of this uncoupling would be the 'freedom' for train drivers to implement the driver's strategy best fit for the occasion.

To illustrate the train-network interaction described above, several case studies (based on simulations) are described. In order to validate the simulation model, the results of these case studies are compared with measurement data. The mean deviation turned out to be $4 \%$, which 
is very small. The maximum deviation of $14 \%$ was found on parts of the network that include freight services. For freight services there is a lack of information about the use of diesel or electrical traction. The model uses only electrical freight trains.

\subsection{BASIC ASSUMPTIONS}

To obtain a fair comparison between two systems $-1,500 \mathrm{~V}_{\mathrm{DC}}$ and $3 \mathrm{kV}_{\mathrm{DC}}$ - other parameters than the system voltage ought to be equal or known unequal. For both systems regenerative braking will be applied.

Section 2 already made clear that train performance depends on the power supply system applied. The train characteristics are not adapted to be equal for both power supply systems but their qualities are used in the simulation: trains are operated with a margin of 5\% to comply with the timetable. This $5 \%$ extra time is uniformly applied to all modes - acceleration, driving, deceleration - of the train between two stations. When a train is delayed, the margin is dropped up to the station where the delay is absent. The recuperation voltage at $1,500 \mathrm{~V}_{\mathrm{DC}}$ is limited for the current rolling stock: BR189, 1,900 $\mathrm{V}_{\mathrm{DC}}, \mathrm{VIRM}, 1,925 \mathrm{~V}_{\mathrm{DC}}$ and SLT, 1,950 $\mathrm{V}_{\mathrm{DC}}$. According to EN50163 the maximum recuperation voltage for a $1,500 \mathrm{~V}_{\mathrm{DC}}$ system is $1,950 \mathrm{~V}_{\mathrm{DC}}$. The recuperation voltage for a $3 \mathrm{kV}_{\mathrm{DC}}$ system is $3,900 \mathrm{~V}_{\mathrm{DC}}$. This voltage is applied to the $3 \mathrm{kV}$ train characteristics. The substation impedance at $3 \mathrm{kV}_{\mathrm{DC}}$ is four times higher than that at $1,500 \mathrm{~V}_{\mathrm{DC}}$ for a comparable substation. All substations in the existing $1,500 \mathrm{~V}_{\mathrm{DC}}$ network are used as substations in the $3 \mathrm{kV}_{\mathrm{DC}}$ network.

\subsection{CASE STUDIES}

The simulation model used in the case studies is based on part of the network in the Netherlands: the connection between Utrecht and Den Bosch including all lines connecting to Den Bosch. This model represents the complete network [3].

The energy delivered by the substations is related to the $1,500 \mathrm{~V}_{\mathrm{DC}}$ system without recuperation: $1,500 \mathrm{~V}_{\mathrm{DC}}$ recuperation $85 \%, 3 \mathrm{kV}_{\mathrm{DC}}$ recuperation $95 \%$ and $3 \mathrm{kV}_{\mathrm{DC}}$ recuperation $75 \%$ (see Fig. 3). The difference in recuperation energy between $1,500 \mathrm{~V}_{\mathrm{DC}}$ and $3 \mathrm{kV}_{\mathrm{DC}}$ can be explained by two factors: a reduced recuperation voltage for VIRM and BR189, and a reduced susceptibility for recuperative energy by the $1,500 \mathrm{~V}_{\mathrm{DC}}$ system. The first factor plays a minimal role, because the VIRM and BR189 represent intercity and freight services and therefore represent a minority in recuperation energy in the network. The stop service (SLT) on the contrary has no diverting limitation. The susceptibility for recuperation energy is demonstrated in Fig. 4 for both power supply systems.

Figure 4 demonstrates the limited ability of the $1,500 \mathrm{~V}_{\mathrm{DC}}$ system to deliver the demanded power and to receive the regenerative power. It also illustrates the ability of the $3 \mathrm{kV}_{\mathrm{DC}}$ system not only to deliver a higher power demand, but also to receive the complete recuperation power. Measurements of Dutch Railways confirm that up to $50 \%$ of the regenerative power of intercity services between Utrecht and Den Bosch could not be fed back into the network.

A further increase of the regenerative power is thus only feasible in the $3 \mathrm{kV}_{\mathrm{DC}}$ network. To investigate if an increase of density of rolling stock will increase the susceptibility of the $1,500 \mathrm{~V}_{\mathrm{DC}}$ for regenerative energy a high frequency timetable between Utrecht and Den Bosch was introduced (PHS 8/8), using the same infrastructure as the 2013 timetable [4]. In Fig. 5 the result of the simulation study is presented in comparison with the 2013 timetable.

The efficiency of the $1,500 \mathrm{~V}_{\mathrm{DC}}$ system is between $88 \%$ (PHS 8/8) and $89 \%$ (timetable 2013) compared with 94\% (PHS 8/8) and 95\% (timetable 2013) for the $3 \mathrm{kV}_{\mathrm{DC}}$ system. The increased number of trains has not led to an increase in recuperation energy in the $1,500 \mathrm{~V}_{\mathrm{DC}}$ system (relative). 


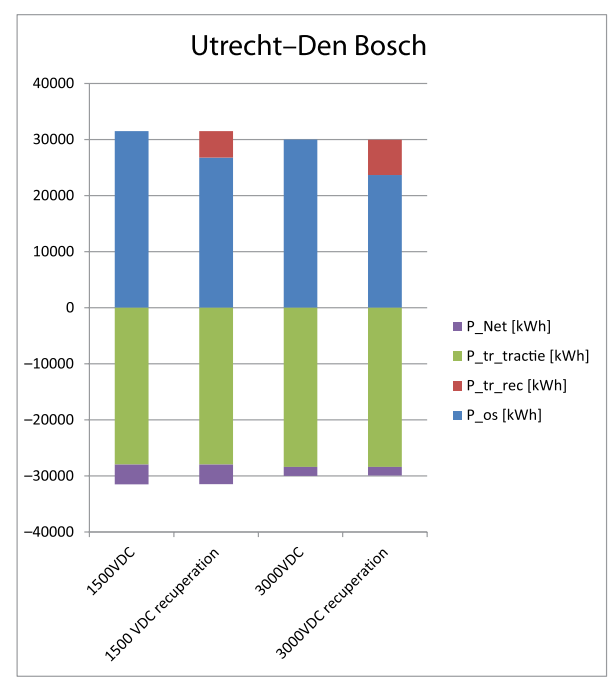

Figure 3: Energy consumption of $1 \mathrm{~h}$ of the complete network. Timetable 2013.

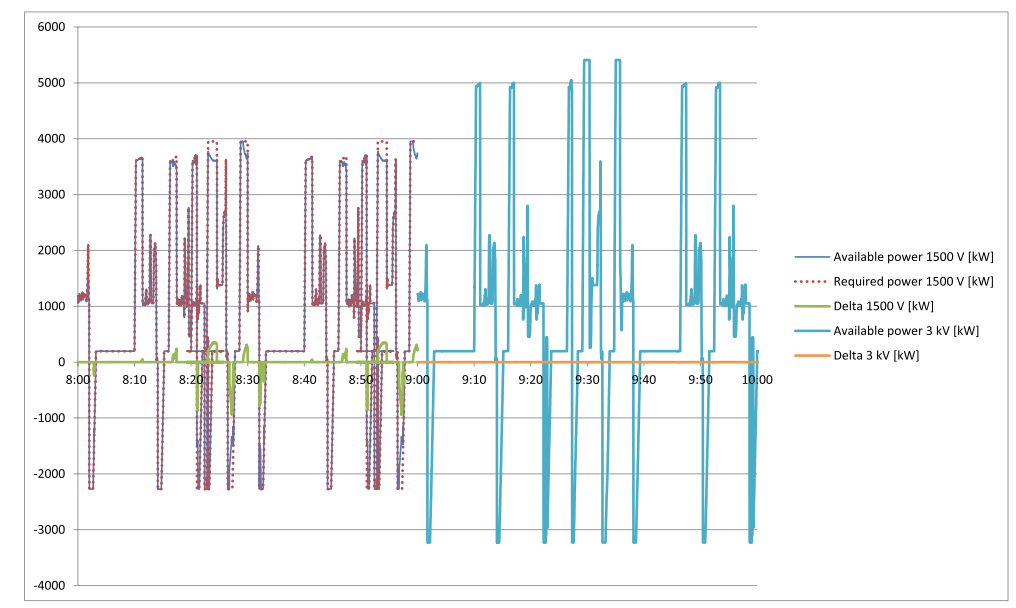

Figure 4: Train results 1,500 $\mathrm{V}_{\mathrm{DC}}(8: 00-9: 00) 3 \mathrm{kV}_{\mathrm{DC}}$ (9:00-10:00). Timetable 2013.

Besides the Utrecht-Den Bosch network, three regional lines (Heuvellandlijn, Betuwelijn and Valleilijn) were studied [4]. Is the advantage of the $3 \mathrm{kV}_{\mathrm{DC}}$ over the $1,500 \mathrm{~V}_{\mathrm{DC}}$ network on the conventional lines also valid on regional lines? One of this regional lines, the Betuwelijn - mostly a single-track layout - is crossing the conventional line Utrecht-Den Bosch at Geldermalsen. Figure 6 demonstrates the result of individual regenerative power of rolling stock, which leads again to the conclusion that a $1,500 \mathrm{~V}_{\mathrm{DC}}$ network is not very susceptible to regenerative energy.

Although the timetable on a single-track layout is blocking the possibility to regenerate energy close by, the $3 \mathrm{kV}_{\mathrm{DC}}$ system is able to provide the regenerative energy towards the line Utrecht-Den Bosch: $17 \%$ less energy supplied by the substations on the Betuwelijn compared with the $1,500 \mathrm{~V}_{\mathrm{DC}}$ variant. 


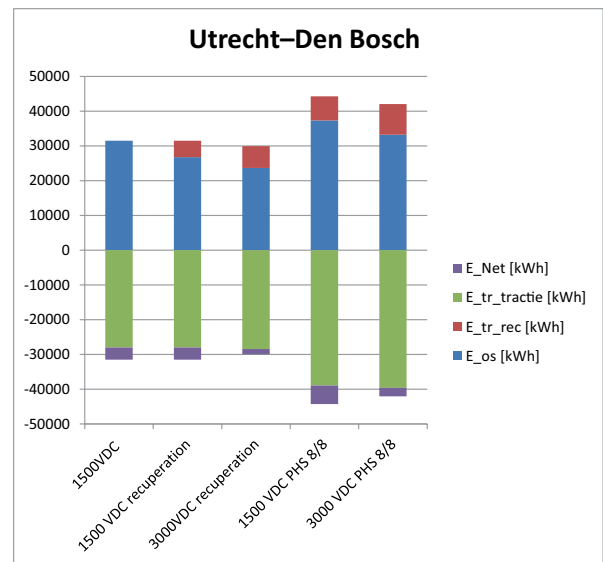

Figure 5: Simulation results of the energy consumption of $1 \mathrm{~h}$ of the complete network. Timetable 2013 and increased frequency (PHS 8/8).

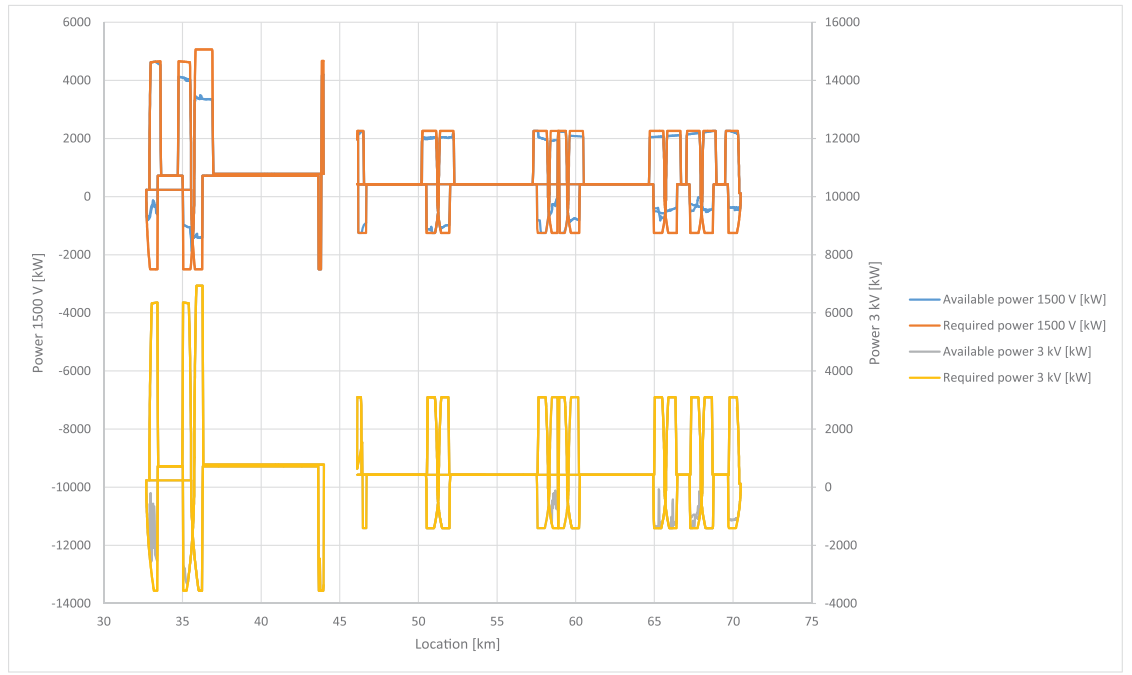

Figure 6: Train performance, above $1,500 \mathrm{~V}_{\mathrm{DC}}$, beneath $3 \mathrm{kV}_{\mathrm{DC}}$.

The Valleilijn is a regional line of $18 \mathrm{~km}$ single-track line length without own substations, connecting two conventional lines. The absence of substations enables regenerative braking for both power supply systems, although the difference between the power supply systems on regenerative braking is still present: the regenerative power under $1,500 \mathrm{~V}_{\mathrm{DC}}$ is limited. The tractive effort performance under $1,500 \mathrm{~V}_{\mathrm{DC}}$ is also limited on major parts of the Valleilijn. For that reason both power supply systems perform with the same energy efficiency. The result of the regional line in the complete network is demonstrated in Fig. 7. Because of the small amount of energy on the regional line compared to the complete network, the overall result is equal to conventional lines.

The Heuvellandlijn is a double-track regional line of $22 \mathrm{~km}$ with substations, connecting two conventional lines. The power supply systems do not limit the performance - tractive and 


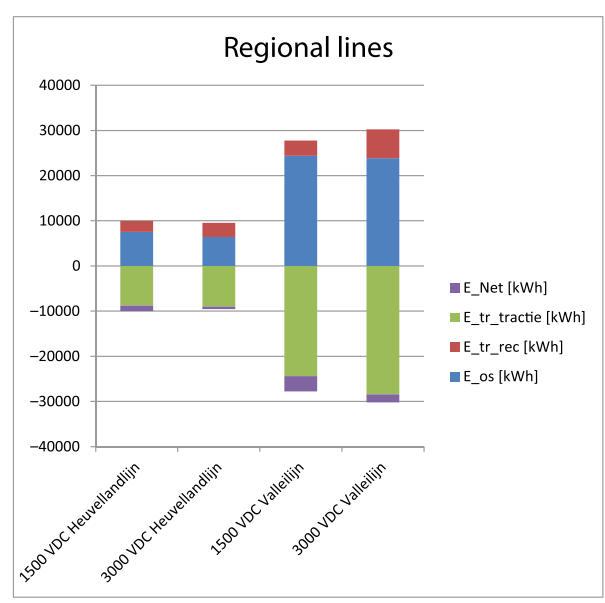

Figure 7: Simulation results of the energy consumption of $1 \mathrm{~h}$ of the regional networks. Timetable 2013.

regenerative - on this regional line. Figure 7 shows that both power supply systems perform with the same energy efficiency.

The main conclusion of this section is that a $1,500 \mathrm{~V}_{\mathrm{DC}}$ power supply system negatively influences the performance of rolling stock. The network decreases the tractive effort as well as the regenerative energy and therefore creates an energy opportunity gap. Increase of the frequency in the timetable only strengthens these effects. Increasing the regenerative energy which is possible according to Section 2 - does not increase the energy efficiency because the $1,500 \mathrm{~V}_{\mathrm{DC}}$ network is already overloaded by the regenerative energy supplied by the trains.

The $3 \mathrm{kV}_{\mathrm{DC}}$ network, on the other hand, offers complete susceptibility for not only tractive effort but also regenerative energy and therefore avoids an energy opportunity gap. Furthermore, increasing regenerative energy as mentioned in Section 2 will lead to a higher energy efficiency.

\section{OPERATIONAL STRATEGIES}

The results of Sections 2 and 3 give rise to the question whether operational strategies should differ for the two power supply systems. In a 1,500 $\mathrm{V}_{\mathrm{DC}}$ system operational strategies aimed at increasing the regenerative energy will not lead to a higher energy efficiency of the system. In a $3 \mathrm{kV}_{\mathrm{DC}}$ system, however, there is still room for an increase of regenerative energy. Operational strategies to increase this energy will lead to a higher energy efficiency of the system.

The previous two sections also revealed that the energy opportunity gap is not only network dependable but also dependent on the use of the individual rolling stock. In order to get a clear view of their effect on the energy efficiency of the two power supply systems, several parameters (coasting, a wide variety of decelerations, speed restriction and catenary coupling) were studied. In Fig. 8 comparisons are made between coasting, recuperation and the combination of coasting and recuperation.

In the current situation in the Netherlands, coasting is an attractive strategy to increase energy efficiency. (In 2013 about 50\% of the rolling stock was capable to regenerate power back to the network.) The result of coasting is equal to having all trains equipped with regenerative braking facilities. The combination of coasting and regenerative braking increases 


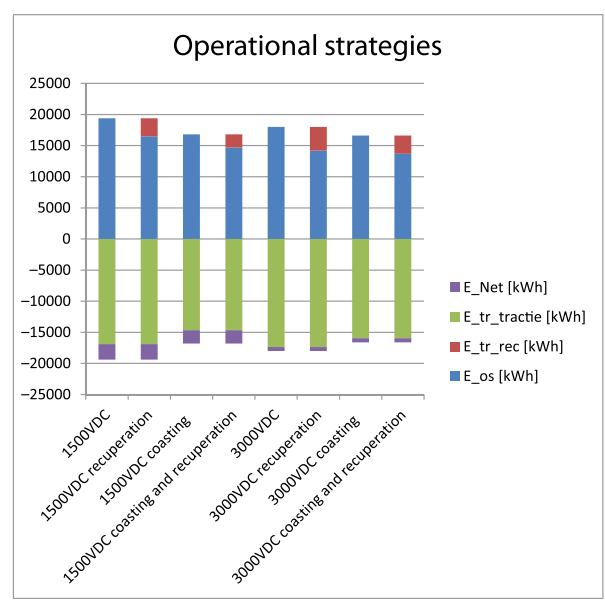

Figure 8: Simulation results of the energy consumption of $1 \mathrm{~h}$ of operational strategies.

the efficiency furthermore. The coasting strategy of Dutch Railways is - based on the status of the rolling stock - a conscious choice in reducing energy consumption in railways. The outcome of Sections 2 and 3 demonstrates that obtaining higher levels of regenerative energy in a $1,500 \mathrm{~V}_{\mathrm{DC}}$ system will not lead to an increase in energy efficiency of the system. The combination of coasting above $100 \mathrm{~km} / \mathrm{h}$ and regenerative braking below $100 \mathrm{~km} / \mathrm{h}$ is a wellworking strategy for a $1,500 \mathrm{~V}_{\mathrm{DC}}$ system.

Despite the success of this strategy in a $1,500 \mathrm{~V}_{\mathrm{DC}}$ system, a $3 \mathrm{kV}_{\mathrm{DC}}$ system needs another strategy to maximize the increase of energy efficiency. The $3 \mathrm{kV}_{\mathrm{DC}}$ system is able to couple high performance - substantial higher power per train compared with $1,500 \mathrm{~V}_{\mathrm{DC}}$, and reduced travelling time - with high efficiency (due to its high susceptibility for regenerative energy).

Introducing the $3 \mathrm{kV}_{\mathrm{DC}}$ system in the Netherlands will disconnect energy efficiency from the operational strategies (regenerative braking or coasting combined with regenerative braking). This conclusion is based on the $60 \%$ regenerative energy of Section 2. If this regenerative energy can be increased, regenerative braking will be preferable to coasting.

\section{SOCIAL COST-BENEFIT ANALYSIS}

This method has been used for an indication of the social cost-benefit analysis of the introduction of a $3 \mathrm{kV}_{\mathrm{DC}}$ traction power supply system in the Netherlands [5]. Fifty percent of the benefit consists of energy efficiency. The cost of the system changeover is calculated at 400 million euros for infrastructure and a couple of 100 million euros for rolling stock [6]. Based on the energy efficiency calculations, the ROI period is 15 years [2].

\section{CONCLUSION}

This article described a three-level method to obtain energy efficiency in railways. The application of this method on the possible system changeover in the Netherlands shows that a system changeover should also lead to a 'changeover' in operational strategy: energy efficiency based on coasting in a $1,500 \mathrm{~V}_{\mathrm{DC}}$ system has to be replaced by regenerative braking in a $3 \mathrm{kV}_{\mathrm{DC}}$ system. To improve the efficiency furthermore the way of braking has to be improved by introducing optimized deceleration for regenerative braking. For stop services in the Netherlands an improvement of $40 \%$ of the total regenerative energy is feasible. So, operational strategy has to be tuned to the traction power supply system. A changeover from 
$1,500 \mathrm{~V}_{\mathrm{DC}}$ to $3 \mathrm{kV}_{\mathrm{DC}}$ - based on the outcome of conservative energy efficiency calculations will give ROI within 15 years.

Using the method discussed in this article, railway companies can easily determine the most efficient way to increase energy efficiency in their network and perform a well-founded social cost-benefit analysis.

\section{REFERENCES}

[1] Steenis, N.H. van, Monitoring Train Performance in Case of Low Adhesion, Enschede: University of Twente, The Netherlands, 11 June 2010.

[2] Dutch Government, Guideline for Social Cost Benefit Analysis. Ministry of Economic Affairs \& Ministry of Infrastructure and Transport, The Hague, 2000.

[3] Paulussen, R.M., Electrical Energy Simulations on Behalf of Introduction of $3 \mathrm{kV} V_{D C}$ Traction Power Supply, Amersfoort: ARCADIS Netherlands BV, 26 September 2014.

[4] Paulussen, R.M., Electrical Energy Simulations on Behalf of Introduction of $3 \mathrm{kV}$ Traction Power Supply: Regional Lines, Amersfoort: ARCADIS Netherlands BV, 27 October 2014.

[5] Zoeteman, A., Harve, F. ten, \& Ploeg, T., Societal Cost benefit Analysis $3 \mathrm{kV}$ and $1500 \mathrm{~V}$ Traction Power Supply, Utrecht: ProRail, 2014. .

[6] Zoeteman, A., Harve, F. ten, \& Ploeg, T., Migrating to DC $3 \mathrm{kV}$ traction power supply for Dutch Railways - A feasibility analysis. Elektrische Bahnen 114 (2016) Heft 1-2.

[7] Harve, G.F. ten., Sustainable Traction Supply, Utrecht: ProRail, 2012.

[8] Paulussen, R.M., Electrical Energy Simulations on Behalf of Introduction of 3 kVDC Traction Power Supply: PHS-study, Amersfoort: ARCADIS Netherlands BV, 26 September 2014.

[9] Welvaarts, J., 3000V Traction Energy Supply: Travel Time and Recuperation Effects, Utrecht: Lloyd's Register Rail, 2014. 